\title{
Population Behavior Analysis of dspE and peID Regulation in Erwinia chrysanthemi 3937
}

\author{
Quan Peng, ${ }^{1}$ Shihui Yang, ${ }^{1}$ Amy O. Charkowski, ${ }^{2}$ Mee-Ngan Yap, ${ }^{2}$ Douglas A. Steeber, ${ }^{1}$ Noel T. Keen, ${ }^{3}$ \\ and Ching-Hong Yang ${ }^{1}$
}

\begin{abstract}
${ }^{1}$ Department of Biological Sciences, University of Wisconsin-Milwaukee 53211, U.S.A.; ${ }^{2}$ Department of Plant Pathology, University of Wisconsin-Madison 53706, U.S.A.; ${ }^{3}$ Department of Plant Pathology, University of California, Riverside 92521, U.S.A.
\end{abstract}

Submitted 12 August 2005. Accepted 19 December 2005.

\begin{abstract}
Erwinia chrysanthemi 3937 (Ech3937) is a phytopathogenic bacterium with a wide host range. The pectinolytic enzymes secreted by the bacterium and the type III secretion system (T3SS) are essential for full virulence. We used the green fluorescent protein gene as a reporter to investigate the expression of $d s p E$ (a putative T3SS effector) and pelD (a major pectin-degrading enzyme) in populations of Ech3937 under different conditions. Gene expression was analyzed by measuring the fluorescence intensity of individual cells with a fluorescence-activated cell sorter. Ech3937 $d s p E$ was induced in minimal medium (MM) with only a portion of Ech3937 cells $(43.03 \%)$ expressing $d s p E$ after $12 \mathrm{~h}$ of culture. The nutrient-rich King's medium $B$ did not fully eliminate the expression of $d s p E$; a small percentage of Ech3937 cells $(5.55 \%)$ was able to express $d s p E$ after $12 \mathrm{~h}$ of culture in this medium. In all, $68.95 \%$ of Ech3937 cells expressed pelD after $12 \mathrm{~h}$ of culture in MM supplemented with polygalacturonic acid (PGA). However, 96.34\% of Ech131 cells (an hrpL deletion mutant of Ech3937) expressed pelD after $12 \mathrm{~h}$ of culture in MM supplemented with PGA. In potato tubers, $6.32 \%$ of the bacterial cells expressed $d s p E 2 \mathrm{~h}$ after inoculation, whereas only $0.25 \%$ of the cells expressed pelD. However, after $24 \mathrm{~h}$, the percentage of cells expressing pelD $(68.48 \%)$ was approximately 3.5 times that of cells expressing $d s p E(19.39 \%)$. In contrast to potato tubers, similar proportion of Ech3937 cells expressing $d s p E$ $(39.34 \%)$ and pelD $(40.30 \%)$ were observed in Chinese cabbage $24 \mathrm{~h}$ after inoculation. From promoter activity and real-time quantitative results, the expression of pelD in Ech3937 was demonstrated to be downregulated by HrpL in MM supplemented with PGA.
\end{abstract}

Additional keyword: pectinase.

Erwinia chrysanthemi is a phytopathogenic bacterium that attacks a wide range of plant species. It secretes a set of pectindegrading enzymes, such as pectin esterases, polygalacturonases, pectate lyases, and pectin lyases, through a type II system leading to a loss of structural integrity of plant cell walls (Boccara and Chatain 1989; Kazemi-Pour et al. 2004; Py et al.

This work is dedicated to Professor Noel T. Keen, who passed away on 18 April 2002.

Q. Peng and S. Yang contributed equally in this work.

Corresponding author: C.-H. Yang; Telephone: +1-414-229-6331; Fax: +1-414-229-3926; E-mail: chyang@uwm.edu
1999; Roy et al. 1999; Shevchik and Hugouvieux-Cotte-Pattat 1997, 2003; Shevchik et al. 1999). In addition to the pectinolytic capacity and soft-rot development of $E$. chrysanthemi in plant hosts, recent reports showed that the type III secretion system (T3SS) also is essential for full virulence of the bacterium (Yang et al. 2002; Yang et al. 2004). Studies in E. chrysanthemi strain EC16 demonstrated a role for the T3SS during early stages of pathogenesis (Bauer et al. 1994, 1995; LopezSolanilla et al. 2001). Mutations in the $h r p G, h r c J$, and $h r c C$ genes of E. chrysanthemi 3937 (Ech3937), which encode secretion machinery and translocon components, are reduced in virulence (Yang et al. 2002; Yang et al. 2004). In addition, mutation of the $h r p N$ gene, which encodes a secreted protein, has only limited effects on virulence, suggesting that other as yet unidentified Hrp-translocated virulence factors are encoded by Ech3937 (Yang et al. 2002).

The T3SSs, also referred to as the hypersensitive response and pathogenicity (Hrp) systems, deliver bacterial effector proteins into host tissues and are essential virulence determinants in many plant pathogens (Alfano and Collmer 2004; Jin et al. 2003). Although the T3SS has been studied extensively in host-specific biotrophic pathogens, relatively little is known about the roles of T3SS in host-promiscuous necrotrophic pathogens, such as E. chrysanthemi and E. carotovora. In biotrophic pathogens, such as Pseudomonas syringae and Xanthomonas campestris, the hrp genes were tightly controlled by their regulatory system and were induced only in hosts or in an acidic MM that mimics acidic apoplastic condition (Alfano and Collmer 1997). A recent report revealed that an atypical regulation of T3SS was present in E. chrysanthemi strain EC16. The $h r p$ genes of EC16 were expressed in nutrient-rich King's medium B and in minimal salts medium at neutral $\mathrm{pH}$. However, E. chrysanthemi strain 3937 T3SS genes resembled those of many other phytopathogenic bacteria in being repressed in complex medium (Ham et al. 2004).

In contrast to hrp genes, a basal level of pectinase gene expression was observed in E. chrysanthemi in the absence of induction substrates (Hugouvieux-Cotte-Pattat and RobertBaudouy 1992). This first level of pectinase gene induction is important for triggering the pectin catabolic cascade in its pathogenesis. In the presence of pectin and its derivatives from host plants, pectinase synthesis of E. chrysanthemi is further induced, leading to symptom development. Difference in expression of pectinase genes ( $p e l$ ) of E. chrysanthemi was observed among different host tissues and different hosts, which indicates a complex regulation controlling the expression of multiple pectic enzymes. In addition, several regulators, includeing KdgR, PecS, PecT, Pir (plant-inducible regulator), CRP, 
and the rsm system, were reported controlling the expression of multiple pectic enzymes (Castillo and Reverchon 1997; Nasser et al. 1997, 1999; Nomura et al. 1998; Reverchon et al. 1991; Robert-Baudouy et al. 2000).

With the ongoing genome sequencing project of Ech3937, microarray and in vivo expression technology (IVET) were used to study genes of Ech3937 that were upregulated in host plants (Okinaka et al. 2002; Yang et al. 2004). Among these plant upregulated genes, several T3SS genes of Ech3937, including $d s p E, h r p A, h r p B, h r p G$, and $h r p N$, which functioned as effectors, T3SS apparatus components, and translocators respectively, were identified. In addition, several upregulated genes were discovered to be involved in cell wall degradation and sugar transport. These included type II secretory components (Out genes), pectinase (pelD and pelE), oligogalacturonate lyase $(o g l)$, and a rhamnogalacturonide transporter $(r h i T)$.

Although several reports have revealed the expression of $h r p$ and pel genes of E. chrysanthemi in culture media and host plants, the sequential expression and regulation of hrp and pel genes among the individual bacterial cells is unclear (Ham et al. 2004; Hugouvieux-Cotte-Pattat et al. 1996; Rojas et al. 2004; Yang et al. 2004; Yap et al. 2005). In this study, we used fluorescence-activated cell sorting (FACS) to study the expression patterns of $d s p E$ (a putative effector gene) and pelD (an endo-pectate lyase gene) in Ech3937 cells grown in media and in different host plants. The $d s p E$ and pelD genes were chosen because $d s p E$ of Ech3937 is highly homologous to effectors of dspE/avrE in Pseudomonas and other Erwinia spp. and pelD encodes one of the major pectic enzymes in Ech3937 causing effective maceration in host tissues. In this study, we investigated gene expression profiles of $d s p E$ and pelD among individual bacterial cells. In addition, regulatory ties between T3SS and pectinases of E. chrysanthemi were elucidated.

\section{RESULTS}

\section{Expression of $d s p E$ in nutrient-rich medium.}

Nutrient-rich media were reported to suppress T3SS gene expression in several gram-negative plant-pathogenic bacteria
(Alfano and Collmer 2004; Ham et al. 2004). Flow cytometry was used to investigate the $d s p E$ (ASAP ID 19012) and $m r p$ (ASAP ID 20478) gene expression profiles of individual Ech3937 cells in King's B medium (Table 1). Using Ech3937(pPROBE-AT) (Ech3937 carrying plasmid pPROBEAT) as a baseline control, green fluorescent protein (GFP) intensity was determined on gated populations of bacterial cells by flow cytometry. Bacterial cells were identified and selected for analysis based on characteristic forward and side light scatter properties. Flow cytometry results were analyzed using Cell Quest software (BD Biosiences). The mrp, used as a control as a constitutively expressed gene in this study, contained an ATPase conserved domain (2e-06). Our FACS results showed a proportion of $99.47 \%$ of the total Ech3937 cells containing Pmrp expressed GFP in King's B medium at $12 \mathrm{~h}$. In addition, no significant difference in mrp expression was observed between Ech3937 (Pmrp) and Ech131 (Pmrp) in FACS assays (data not shown).

The nutrient-rich King's B medium did not fully suppress the expression of $d s p E$; a small proportion of Ech3937 $(\mathrm{P} d s p E)$ cells $(5.55 \%)$ expressed GFP with a mean fluorescence intensity (MFI) of 106.85 at $12 \mathrm{~h}$ (Table 2). The MFI of total bacterial cells at $12 \mathrm{~h}$ (including GFP-expressing and non-GFP-expressing cells) was 8.61 in this medium. Little if any fluorescence was detected in Ech131 (PdspE). Only $0.02 \%$ of Ech131 (PdspE) cells expressed GFP with an MFI of 25.09 at $12 \mathrm{~h}$. The MFI of the total bacterial cells at $12 \mathrm{~h}$ was 1.96 . The Ech3937 (Pmrp) cells were expressed at a rate of $99.47 \%$, with an MFI of 74.39 at $12 \mathrm{~h}$ in the GFP-expressing cells. The MFI of total bacterial cells was 74.01 .

\section{Expression of $d s p E$ and $p e l D$ in minimal medium.}

Ech3937 cells containing $d s p E$ and pelD (ASAP ID 19648) GFP promoter reporter plasmids (PdspE and PpelD) grown in minimal medium (MM) had different gene expression profiles in individual cells. The Ech3937 cells containing $\mathrm{P} d s p E$ were expressed at a proportion of $1.94,7.77,43.03$, and $56.49 \%$ of the total bacterial cells with an MFI of 42.84, 76.48, 173.24, and 229.2 at $0,8,12$, and $24 \mathrm{~h}$, respectively (Table 3). A puta-

Table 1. Strains, plasmids, and DNA primers used in this study

\begin{tabular}{|c|c|c|}
\hline Strains, plasmids and primers & Characters or sequences $\left(5^{\prime} \text { to } 3^{\prime}\right)^{a}$ & Reference or source \\
\hline \multicolumn{3}{|l|}{$\begin{array}{c}\text { Strains } \\
\end{array}$} \\
\hline \multicolumn{3}{|l|}{ Escherichia coli } \\
\hline JM109 & $\begin{array}{l}\text { end } \mathrm{A} 1, \operatorname{rec} \mathrm{A} 1, \text { gyr } \mathrm{A} 96, \text { thi }, \text { hsd } \mathrm{R} 17,\left(\mathrm{r}_{\mathrm{k}}-, \mathrm{m}_{\mathrm{k}}+\right), \operatorname{rel} \mathrm{A} 1, \sup \mathrm{E} 44, \Delta(\text { lac-pro } \mathrm{AB}) \text {, } \\
{\left[\mathrm{F}^{\prime}, \text { traD36, pro } \mathrm{AB}, \text { laq }{ }^{\mathrm{Iq}} \mathrm{Z} \Delta \mathrm{M} 15\right]}\end{array}$ & Promega Corp. \\
\hline \multicolumn{3}{|l|}{ Erwinia chrysanthemi } \\
\hline Ech3937 & Wild type, Saintpaulia (African violet) isolate & N. Hugouvieux-Cotte-Pattat \\
\hline Ech131 & $\Delta h r p L:: k a n ; \mathrm{Km}^{\mathrm{R}}$ & This work \\
\hline WPP96 & $\Delta h r p L_{(\Delta 1-185 \mathrm{aa})}:: \operatorname{aad} A ; \mathrm{Sp}^{\mathrm{R}} / \mathrm{Sm}^{\mathrm{R}}$ & Yap et al. 2005 \\
\hline Ech3937 (PdspE) & Wild-type Ech3937 containing pPROBE-AT inserted with $d s p E$ promoter; $\mathrm{Ap}^{\mathrm{R}}$ & This work \\
\hline Ech3937 (PpelD) & Wild-type Ech3937 containing pPROBE-AT inserted with pelD promoter; $\mathrm{Ap}^{\mathrm{R}}$ & This work \\
\hline Ech3937 (Pmrp) & Wild-type Ech3937 containing pPROBE-AT inserted with $m r p$ promoter; Ap $^{\mathrm{R}}$ & This work \\
\hline Ech131 (PdspE) & $\Delta h r p L::$ kan containing pPROBE-AT inserted with $d s p E$ promoter; $\mathrm{Ap}^{\mathrm{R}} \mathrm{Km}^{\mathrm{R}}$ & This work \\
\hline Ech131 (PpelD) & $\Delta h r p L:$ kan containing pPROBE-AT inserted with pelD promoter; $\mathrm{Ap}^{\mathrm{R}} \mathrm{Km}^{\mathrm{R}}$ & This work \\
\hline \multicolumn{3}{|c|}{ 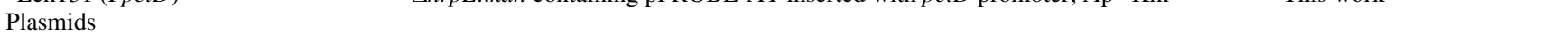 } \\
\hline pGEMT-Easy & Polymerase chain reaction cloning vector, $A p^{R}$ & Promega Corp. \\
\hline pPROBE-AT & Promoter-probe vector, $A p^{R}$ & Miller and Lindow 1997 \\
\hline $\mathrm{P} d s p E$ & 0.9-kb DNA fragment in pBROBE-AT containing $d s p E$ promoter & Yang et al. 2004 \\
\hline PpelD & 0.6-kb DNA fragment in pBROBE-AT containing pelD promoter & Yang et al. 2004 \\
\hline Pmrp & 0.7 -kb DNA fragment in pBROBE-AT containing mrp promoter & This work \\
\hline \multicolumn{3}{|c|}{ 的 } \\
\hline$r p l U$ forward & CGCAACCGGTGAAGCTATTGA & This work \\
\hline$r p l U$ reverse & TTACGGCGACGAAACTTAACGATT & This work \\
\hline pelD forward & TCTCTGGTCATCAAAGGCGTGAGT & This work \\
\hline pelD reverse & GCGGGTGGAATTGTCGATCA & This work \\
\hline$m r p A$ & GTCAGGTGGCACTTTTCGGCTCGAGACGTTCATCCCGGCTCCTTGA & This work \\
\hline$m r p D$ & TGGTACCCTCGAGAAGCTTCCTTGCATTTCGGGCAGGTG & This work \\
\hline
\end{tabular}

${ }^{\mathrm{a}} \mathrm{Km}^{\mathrm{R}}=$ kanamycin resistance, $\mathrm{Ap}^{\mathrm{R}}=$ ampicillin resistance, and $\mathrm{Cm}^{\mathrm{R}}=$ chloramphenicol resistance. 
tive $h r p$ box, 5'-GGAACCGGCGGCGGCGGCATACCACTC AGCA-3', was found in the Ech3937 $d s p E$ promoter region. Very low levels of fluorescence were detected in Ech131 $(\mathrm{P} d s p E$ ) indicating $d s p E$ was regulated by HrpL in Ech3937. A basal level of expression of pelD was observed in Ech3937 (PpelD) and Ech131 (PpelD) with MM medium. Compared with Ech3937 (PpelD), a slightly higher pelD expression was observed in Ech131 (PpelD) at 12 and $24 \mathrm{~h}$ in this medium (Table 3).

\section{Expression of $d s p E$ and pelD of Ech3937 in host plants.}

To investigate the population behavior of hrp and pel expression of Ech3937 cells in different hosts, Ech3937 (PdspE) and Ech3937 (PpelD) were inoculated into Chinese cabbage leaves and potato tubers. In potato tubers, $6.32 \%$ of the Ech3937 $(\mathrm{P} d s p E)$ cells were observed expressing GFP (MFI of 150.87 in the GFP-expressing cells) as early as $2 \mathrm{~h}$ after inoculation. However, only $0.25 \%$ of Ech3937 (PpelD) cells expressed GFP at the same time (17.12 MFI in GFP-expressing cells) (Table 4). Interestingly, in potato tubers, a higher proportion of bacterial cells expressing GFP was observed in Ech3937 (PpelD) cells (68.48\%) than in Ech3937 (PdspE) (19.39\%) at $24 \mathrm{~h}$ after inoculation.

Similarly to the gene expression pattern of Ech3937 in potato tubers, a higher proportion of GFP-expressing cells was observed in Ech3937 (PdspE) than in Ech3937 (PpelD) in the early stage of bacterial infection in Chinese cabbage ( 2 and $4 \mathrm{~h}$ after inoculation with bacteria) (Table 4). However, in contrast to potato tubers, similar proportions of GFP-expressing cells were observed in Ech3937 (PdspE) (39.34\%) and Ech3937 (PpelD) $(40.3 \%)$ at $24 \mathrm{~h}$. Little if any GFP signal was detected in Ech131 ( $\mathrm{P} d s p E)$ in Chinese cabbage leaves and potato tubers, indicating that the expression of $d s p E$ was regulated by $\mathrm{HrpL}$.

\section{HrpL regulates the expression of pectate lyases.}

Promoter activity and real-time quantitative polymerase chain reaction (PCR) assays were used to investigate whether HrpL regulates the expression of pectate lyases in Ech3937. Polygalacturonic acid (PGA) was added into MM medium to induce the expression of pectic enzymes in Ech3937 (PpelD) and Ech131 (PpelD). In the FACS assay, compared with Ech3937 (PpelD), a higher proportion of GFP-expressing bacterial cells and increased fluorescence GFP were observed in Ech131 (PpelD) in the MM medium supplied with PGA (Fig. 1; Table 5). Compared with Ech3937 (PpelD), a higher proportion of GFP-expression also was observed in another Ech3937 hrpL mutant, WPP96 (data not shown). Using a real-time quantitative PCR assay, the relative level of mRNA of pelD in Ech131 was approximately 3.5 -fold higher than in the wildtype Ech3937 at $24 \mathrm{~h}$ in the MM medium supplied with PGA (Fig. 2).

\section{DISCUSSION}

Several expression methods, including Northern blot and Gus activity assays, have been used to detect the expression of pel and hrp genes of E. chrysanthemi; however, the gene expression patterns of individual cells were unknown (Bauer et al. 1995; Laing and Pretorius 1993; Marits et al. 2002; Shevchik et al. 1997). Flow cytometry and FACS, which allows highthroughput investigation of single cells, have been used to interrogate bacteria, yeast, and mammalian cell population behaviors on a single-cell basis (Dye et al. 2005; Park et al. 2005;

Table 2. $d s p E$ and $m r p$ promoter activities of Erwinia chrysanthemi 3937 (Ech3937) in King's medium B broth ${ }^{\mathrm{a}}$

\begin{tabular}{lccc}
\hline Gene promoter $^{\mathbf{b}}$ & Total & GFP $^{+}$ & GFP $^{+} \%$ \\
\hline Ech3937 (PdspE) & $8.61 \pm 5.56$ & $106.85 \pm 13.50$ & $5.55 \pm 3.94$ \\
Ech131 (PdspE) & $1.96 \pm 0.21$ & $25.09 \pm 23.32$ & $0.02 \pm 0.02$ \\
Ech3937 (Pmrp) & $74.01 \pm 9.92$ & $74.39 \pm 10$ & $99.47 \pm 0.04$ \\
Ech3937 (pPROBE-AT) & $1.70 \pm 0.03$ & 0 & 0 \\
\hline
\end{tabular}

${ }^{a}$ Values are a representative of two experiments. Three replicates were used in this experiment. GFP $=$ green fluorescent protein.

${ }^{\mathrm{b}}$ The $d s p E$ promoter activities were compared after $12 \mathrm{~h}$ of culture in King's medium B broth. GFP intensity was determined on gated populations of bacterial cells by flow cytometry. The fluorescence intensities were collected, including average GFP fluorescence intensity of total bacterial cells (Total), average GFP fluorescence intensity of GFP-expressing bacterial cells $\left(\mathrm{GFP}^{+}\right)$, and the percentage of GFP-expressing bacterial cells of the total bacterial cells $\left(\mathrm{GFP}^{+} \%\right)$

Table 3. $d s p E$ and pelD promoter activities of Erwinia chrysanthemi 3937 (Ech3937) and Ech131 in minimal medium ${ }^{\mathrm{a}}$

\begin{tabular}{|c|c|c|c|c|c|}
\hline Gene promoter & Intensities $^{b}$ & $\mathbf{O h}$ & $8 \mathrm{~h}$ & $12 \mathrm{~h}$ & $24 \mathrm{~h}$ \\
\hline \multirow[t]{3}{*}{ Ech3937 (PdspE) } & Total & $2.73 \pm 0.50$ & $8.42 \pm 2.63$ & $76.51 \pm 4.90$ & $131.40 \pm 11.41$ \\
\hline & $\mathrm{GFP}^{+}$ & $42.84 \pm 7.61$ & $76.48 \pm 10.05$ & $173.24 \pm 4.91$ & $229.2 \pm 9.90$ \\
\hline & $\mathrm{GFP}^{+} \%$ & $1.94 \pm 0.55$ & $7.77 \pm 3.57$ & $43.03 \pm 1.58$ & $56.49 \pm 2.57$ \\
\hline \multirow[t]{3}{*}{ Ech131 (PdspE) } & Total & $1.73 \pm 0.04$ & $1.79 \pm 0.07$ & $3.18 \pm 0.09$ & $3.49 \pm 0.05$ \\
\hline & $\mathrm{GFP}^{+}$ & $17.04 \pm 2.90$ & $16.72 \pm 3.41$ & $14.32 \pm 0.66$ & $14.77 \pm 0.26$ \\
\hline & $\mathrm{GFP}^{+} \%$ & $0.17 \pm 0.05$ & $0.09 \pm 0.03$ & $2.52 \pm 0.28$ & $2.99 \pm 0.19$ \\
\hline \multirow[t]{3}{*}{ Ech3937 (PpelD) } & Total & $2.32 \pm 0.10$ & $2.85 \pm 0.26$ & $4.70 \pm 0.19$ & $6.01 \pm 0.32$ \\
\hline & $\mathrm{GFP}^{+}$ & $14.70 \pm 1.30$ & $13.80 \pm 1.66$ & $13.69 \pm 0.53$ & $16.65 \pm 1.04$ \\
\hline & $\mathrm{GFP}^{+} \%$ & $0.06 \pm 0.03$ & $0.71 \pm 0.30$ & $8.27 \pm 2.03$ & $16.02 \pm 1.54$ \\
\hline \multirow[t]{3}{*}{ Ech131 (PpelD) } & Total & $2.62 \pm 0.04$ & $3.56 \pm 0.41$ & $7.13 \pm 0.79$ & $9.98 \pm 0.97$ \\
\hline & $\mathrm{GFP}^{+}$ & $15.89 \pm 0.85$ & $16.41 \pm 1.84$ & $18.25 \pm 4.36$ & $20.38 \pm 2.96$ \\
\hline & $\mathrm{GFP}^{+} \%$ & $0.38 \pm 0.09$ & $4.38 \pm 1.90$ & $16.65 \pm 1.10$ & $30.75 \pm 2.36$ \\
\hline \multirow[t]{3}{*}{ Ech3937 (pPROBE-AT) } & Total & $1.46 \pm 0.02$ & $1.27 \pm 0.01$ & $1.36 \pm 0$ & $1.69 \pm 0.02$ \\
\hline & $\mathrm{GFP}^{+}$ & 0 & 0 & 0 & 0 \\
\hline & $\mathrm{GFP}^{+} \%$ & 0 & 0 & 0 & 0 \\
\hline
\end{tabular}

\footnotetext{
${ }^{a}$ Values are representative of three experiments. Three replicates were used in this experiment. The $d s p E$ and pelD promoter activities in minimal medium broth were compared after $0,8,12$, and $24 \mathrm{~h}$ of culture in minimal medium.

${ }^{\mathrm{b}}$ Green fluorescent protein (GFP) intensity was determined by flow cytometry. The fluorescence intensities were collected, including average GFP fluorescence intensity of total bacterial cells (Total), average GFP fluorescence intensity of GFP-expressing bacterial cells $\left(\mathrm{GFP}^{+}\right)$, and the percentage of GFP-expressing bacterial cells of the total bacterial cells $\left(\mathrm{GFP}^{+} \%\right)$.
} 
Ramprasad et al. 1996; Sergent-Tanguy et al. 2003; Wan and Flavell 2005). We used FACS and a GFP reporter to analyze $d s p E$ and pelD expression in Ech3937 populations in media and plant hosts. In contrast to other detection methods used for measuring the overall gene expression of bacteria (e.g., Northern blot and real-time quantitative PCR), we observed diverse gene expression profiles among individual Ech3937 cells. The mrp gene was constitutively expressed in rich King's B medium, with a majority of cells $(99.47 \%)$ carrying an $\mathrm{mrp}$ promoter reporter plasmid-expressed GFP in media within a $12-\mathrm{h}$ period. The $m r p$ gene encodes a protein with a conserved ATPase domain and is predicted to be involved in cell division and chromosome partitioning. Consistent with other studies, the hrp gene, $d s p E$, is repressed in nutrient-rich King's B medium and

Table 4. $d s p E$ and pelD promoter activities of Erwinia chrysanthemi 3937 (Ech3937) in Chinese cabbage leaves and potato tubers ${ }^{\mathrm{a}}$

\begin{tabular}{|c|c|c|c|c|c|}
\hline Gene promoter & Intensities $^{b}$ & $2 \mathrm{~h}$ & $4 \mathrm{~h}$ & $8 \mathrm{~h}$ & $24 \mathrm{~h}$ \\
\hline \multirow[t]{3}{*}{ Ech3937 (PdspE) in Chinese cabbage leaves } & Total & $5.00 \pm 2.58$ & $28.36 \pm 1.49$ & $24.79 \pm 4.66$ & $37.15 \pm 5.25$ \\
\hline & $\mathrm{GFP}^{+}$ & $111.06 \pm 10.16$ & $165.47 \pm 5.50$ & $116.59 \pm 19.12$ & $90.31 \pm 3.78$ \\
\hline & $\mathrm{GFP}^{+} \%$ & $3.26 \pm 2.14$ & $16.39 \pm 0.37$ & $20.86 \pm 8.36$ & $39.34 \pm 4.32$ \\
\hline \multirow[t]{3}{*}{ Ech3937 (PpelD) in Chinese cabbage leaves } & Total & $1.42 \pm 0.08$ & $2.54 \pm 0.84$ & $5.62 \pm 0.69$ & $29.60 \pm 1.39$ \\
\hline & $\mathrm{GFP}^{+}$ & $17.05 \pm 1.93$ & $22.07 \pm 3.78$ & $26.55 \pm 3.06$ & $70.90 \pm 2.63$ \\
\hline & $\mathrm{GFP}^{+} \%$ & $0.11 \pm 0.02$ & $3.36 \pm 3.15$ & $13.85 \pm 1.89$ & $40.30 \pm 2.54$ \\
\hline \multirow[t]{3}{*}{ Ech3937 (PdspE) in potato tubers } & Total & $11.13 \pm 1.66$ & $18.37 \pm 1.66$ & $47.86 \pm 5.25$ & $18.56 \pm 3.68$ \\
\hline & $\mathrm{GFP}^{+}$ & $150.87 \pm 13.97$ & $159.18 \pm 10.76$ & $223.67 \pm 2.86$ & $83.82 \pm 11.28$ \\
\hline & $\mathrm{GFP}^{+} \%$ & $6.32 \pm 0.65$ & $10.59 \pm 0.32$ & $20.61 \pm 2.32$ & $19.39 \pm 2.02$ \\
\hline \multirow[t]{3}{*}{ Ech3937 (PpelD) in potato tubers } & Total & $2.26 \pm 0.09$ & $3.54 \pm 1.10$ & $18.02 \pm 5.88$ & $73.05 \pm 3.67$ \\
\hline & $\mathrm{GFP}^{+}$ & $17.12 \pm 2.67$ & $19.63 \pm 3.74$ & $38.77 \pm 12.49$ & $105.80 \pm 2.63$ \\
\hline & $\mathrm{GFP}^{+} \%$ & $0.25 \pm 0.08$ & $5.63 \pm 4.76$ & $39.80 \pm 3.23$ & $68.48 \pm 1.93$ \\
\hline \multirow[t]{3}{*}{ Ech131 (P $d s p E)$ in Chinese cabbage leaves } & Total & $1.36 \pm 0.01$ & $1.42 \pm 0.02$ & $1.40 \pm 0.06$ & $1.74 \pm 0.13$ \\
\hline & $\mathrm{GFP}^{+}$ & 0 & 0 & 0 & $26.83 \pm 10.64$ \\
\hline & $\mathrm{GFP}^{+} \%$ & 0 & 0 & 0 & $0.26 \pm 0.08$ \\
\hline \multirow[t]{3}{*}{ Ech131 $(\mathrm{P} d s p E)$ in potato tubers } & Total & $1.48 \pm 0.02$ & $1.48 \pm 0.02$ & $1.80 \pm 0.11$ & $1.95 \pm 0.05$ \\
\hline & $\mathrm{GFP}^{+}$ & 0 & 0 & 0 & $12.16 \pm 1.14$ \\
\hline & $\mathrm{GFP}^{+} \%$ & 0 & 0 & 0 & $0.08 \pm 0.05$ \\
\hline \multirow[t]{3}{*}{ Ech3937 (pPROBE-AT) in Chinese cabbage leaves } & Total & $1.25 \pm 0.07$ & $1.32 \pm 0.01$ & $1.37 \pm 0.03$ & $1.42 \pm 0.04$ \\
\hline & $\mathrm{GFP}^{+}$ & 0 & 0 & $78.88 \pm 80.18$ & 0 \\
\hline & $\mathrm{GFP}^{+} \%$ & 0 & 0 & $0.03 \pm 0.03$ & 0 \\
\hline \multirow[t]{3}{*}{ Ech3937 (pPROBE-AT) in potato tubers } & Total & $1.41 \pm 0.04$ & $1.30 \pm 0.02$ & $1.54 \pm 0.09$ & $1.74 \pm 0.11$ \\
\hline & $\mathrm{GFP}^{+}$ & 0 & 0 & 0 & 0 \\
\hline & $\mathrm{GFP}^{+} \%$ & 0 & 0 & 0 & 0 \\
\hline
\end{tabular}

${ }^{\mathrm{a}}$ The $d s p E$ and pelD promoter activities in different hosts were compared after 2, 4, 8, and $24 \mathrm{~h}$ of inoculation. Three replicate plants were used for each treatment.

${ }^{\mathrm{b}}$ Green fluorescent protein (GFP) intensity was determined by flow cytometry. The fluorescence intensities were collected, including average GFP fluorescence intensity of total bacterial cells (Total), average GFP fluorescence intensity of GFP-expressing bacterial cells $\left(\mathrm{GFP}^{+}\right)$, and the percentage of GFP-expressing bacterial cells of the total bacterial cells $\left(\mathrm{GFP}^{+} \%\right)$.
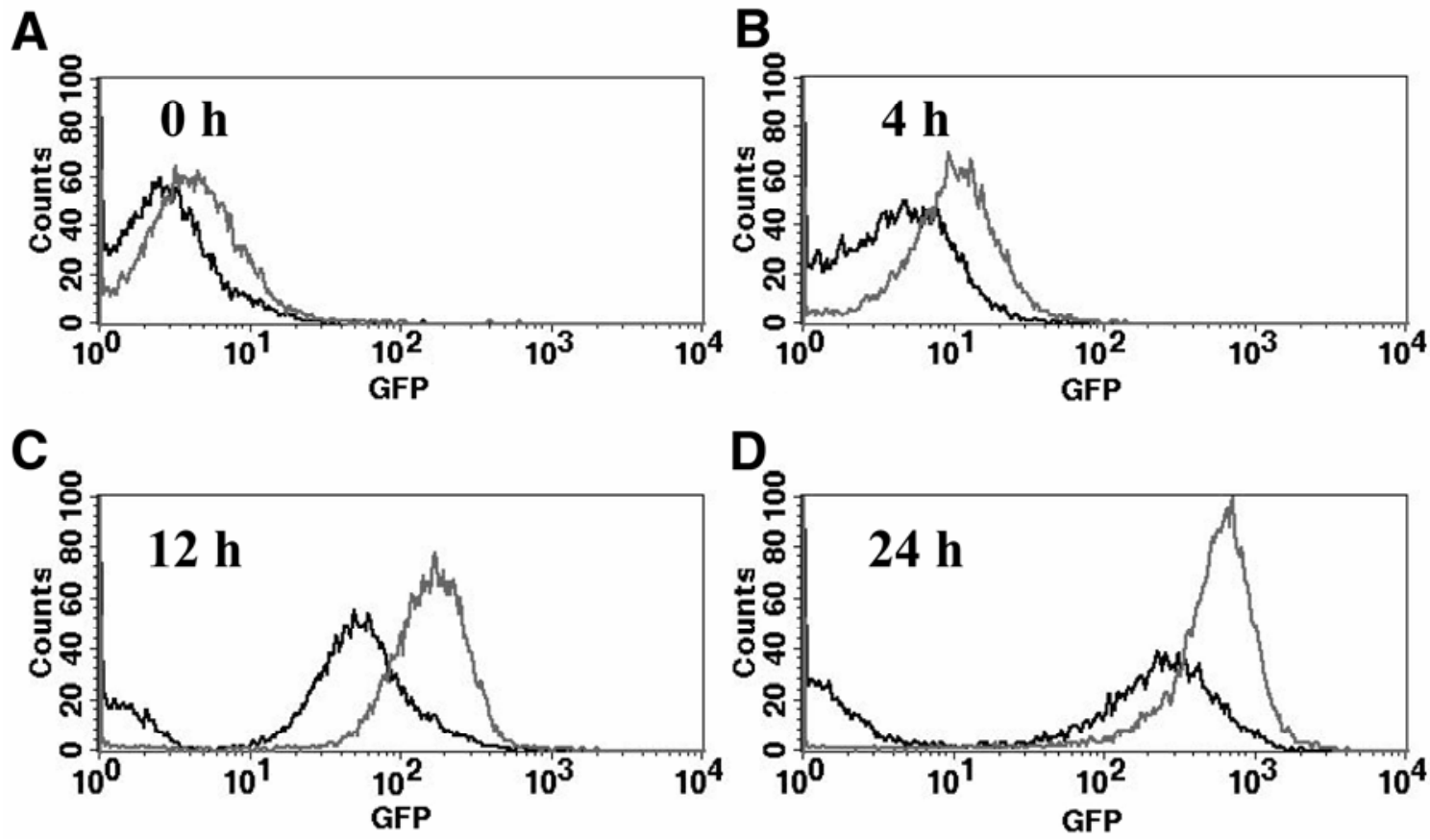

Fig. 1. Erwinia chrysanthemi 3937 (Ech3937) pelD promoter activity (green fluorescent protein [GFP] intensity of plasmid pPpelD) was compared in wildtype Ech3937 (black lines) and the $\Delta h r p L$ mutant, Ech131 (gray lines) after A, 0, B, 4, C, 12, and D, 24 h of culture in a pectate lyase inducible condition (minimal medium with $1 \%$ polygalacturonic acid). GFP intensity was determined by flow cytometry. No fluorescence was observed in the bacteria containing the pPROBE-AT vector alone (not shown). 
induced in MM (Alfano and Collmer 2004; Ham et al. 2004). However, it is worth mentioning that the rich medium did not totally eliminate the expression of $d s p E$; a small proportion of Ech3937 cells carrying PdspE (5.55\%) still was able to be expressed in the King's B medium. Similar to the $h r p L$ and $h r p N$ expression pattern in E. chrysanthemi strain EC16 (Ham et al. 2004), a higher GFP expression was observed in Ech3937 $(\mathrm{P} d s p E)$ cells in late log phase. In addition, a higher expression of the pelD gene also was observed in the later stage of bacterial growth, which was consistent with other reports (Jafra et al. 1999; Robert-Baudoy et al. 2000). From our FACS assay, a considerable proportion of the bacterial cells carrying PdspE (44 to 57\%) and PpelD (31 to 37\%) did not produce a detectable GFP signal under inducing conditions (MM and MM supplied with PGA) at the 12- and 24-h period (Tables 3 and 5). Interestingly, the Ech131 (PpelD) cells expressing GFP fluorescence in MM supplemented with PGA at 12 and $24 \mathrm{~h}$ were 96.34 and $97.76 \%$, respectively (Table 5), indicating that the $\mathrm{HrpL}$ is the factor limiting the pelD expression among individual bacterial cells. There is no obvious Hrp box identified in the pelD promoter region, indicating an indirect tie between HrpL and pelD regulation.

Under different conditions (e.g., MMs or plant hosts), only a small portion of the Ech3937 carrying PdspE were induced early in growth. Although a higher proportion of GFP-expressing cells was observed in Ech3937 (PdspE) at the later stage of induction, the percentage of the cells induced still was significantly lower than the Ech3937 (Pmrp) cells. The promoter probe reporter vector, pPROBE-AT, produces an extremely

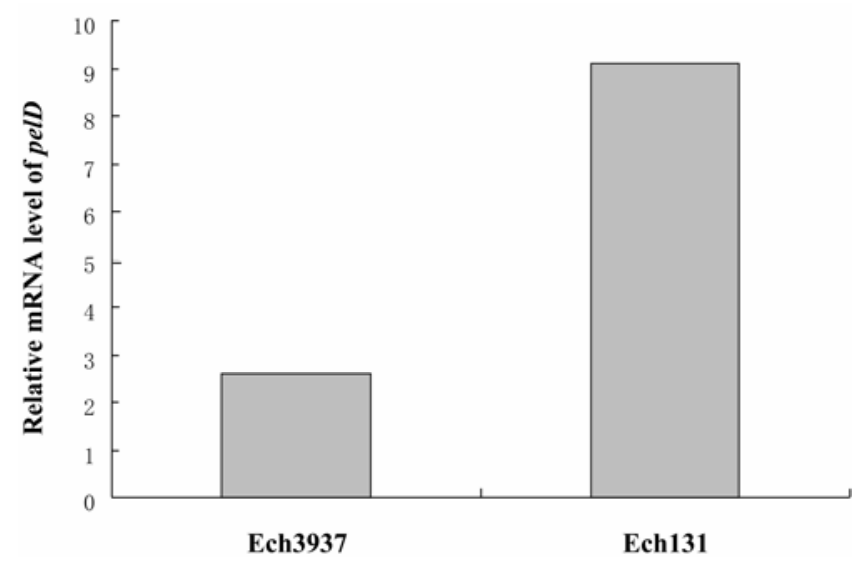

Fig. 2. Relative level of mRNA of pelD in Erwinia chrysanthemi 3937 (Ech3937) and Ech131 ( $\Delta h r p L$ mutant of Ech3937) grown for $24 \mathrm{~h}$ in a minimal medium supplied with $1 \%$ polygalacturonic acid. The amount of pelD mRNA was examined by real-time polymerase chain reaction assay. Similar results were observed in two individual experiments. stable GFP (Miller et al. 2000). Once the cells have produced GFP, they are fluorescent at later time points even though the cells have stopped generating GFP. In this study, the percentage of GFP-expressing cells at different time periods can be considered as a sum of $E$. chrysanthemi cells that expressed GFP or are expressing GFP from initial inoculation point until the cells are harvested. In our results, a considerable proportion of Ech3937 cells never expressed $d s p E$ during the 24-h period in different media and host plants. The reason for this phenomenon is unknown. One attractive hypothesis is that, for Ech3937 to successfully establish in its hosts, individual bacterial cells might play different roles and work together as a community effort to ensure disease development. At the first stage of the invasion, there is a small proportion of the bacteria cells responding to the stimuli (e.g., in this study, a small portion of Ech3937 cells with their hrp genes upregulated in the MM and plant hosts). Once the environments are considered to be suitable for pathogen infection, a higher proportion of the bacterial cells with their virulence genes are further upregulated.

During plant infection with E. chrysanthemi, pelD, pelE, and pelI were reported to be highly expressed in potato tubers, whereas pelA, pelB, pelC, pelL, pelZ, and pemA were moderately expressed (Robert-Baudoy et al. 2000). Using a Gus reporter, Jafra and associates (1999) discovered that pelD of $E$. chrysanthemi was highly induced in potato tubers after $20 \mathrm{~h}$ post inoculation. Our study also revealed that a significant increase of Ech3937 pelD expression, both in proportion of cells expressing GFP and GFP intensity, occurred in potato tubers $24 \mathrm{~h}$ post inoculation. In contrast to pelD, the GFP intensity and the proportion of bacterial cells expressing GFP in Ech3937 (PdspE) were significantly reduced at $24 \mathrm{~h}$ once maceration symptoms became apparent. It is unlikely that DspE, which probably has a virulence function dependent upon its secretion into living plant cells, would promote bacterial virulence once the cells have been killed by other virulence proteins, such as the Pels.

Different expression patterns of $d s p E$ and pelD were observed in Ech3937 between Chinese cabbage and potato tubers. Although a significant increase of pelD expression also was observed at $24 \mathrm{~h}$ in Chinese cabbage, compared with potato tubers, a lower proportion of the bacterial cells expressing pelD was observed at that time. In contrast to the expression pattern of $d s p E$ in potato tubers, a relatively higher proportion of Ech3937 cells expressing $d s p E$ was observed at $24 \mathrm{~h}$ in Chinese cabbage, although the GFP intensity was slightly reduced. The reasons for a lower proportion of pelD expression of Ech3937 cells in Chinese cabbage $(40.3 \%)$ than in potato tubers $(68.48 \%)$ but a higher proportion of $d s p E$ expression cells in Chinese cabbage $(39.34 \%)$ than in potato tubers $(19.39 \%)$ at $24 \mathrm{~h}$ are uncertain. One logical explanation is that potato tubers are a nutrient-rich storage organ. The T3SS of Ech3937 might

Table 5. Erwinia chrysanthemi 3937 (Ech3937) pelD promoter activities of wild-type Ech3937 and its hrpL deletion mutant, Ech131, grown in minimal medium with $1 \%$ polygalacturonic acid ${ }^{\mathrm{a}}$

\begin{tabular}{lrrccc}
\hline Gene promoter, intensities $^{\mathbf{b}}$ & $\mathbf{0 ~ h}$ & $\mathbf{4 h}$ & $\mathbf{8} \mathbf{h}$ & $\mathbf{1 2} \mathbf{h}$ & $\mathbf{2 4} \mathbf{h}$ \\
\hline Ech3937 (PpelD) & & & & & \\
$\quad$ Total & $3.01 \pm 0.32$ & $4.20 \pm 0.06$ & $13.60 \pm 0.63$ & $38.57 \pm 1.83$ & $142.86 \pm 4.28$ \\
GFP $^{+}$ & $13.15 \pm 0.16$ & $14.00 \pm 0.14$ & $21.60 \pm 0.52$ & $55.30 \pm 2.50$ & $228.77 \pm 22.96$ \\
GFP $^{+}$ & $3.10 \pm 1.90$ & $6.23 \pm 0.20$ & $56.29 \pm 1.88$ & $68.95 \pm 0.88$ & $62.70 \pm 7.03$ \\
Ech131 (PpelD) & & & & \\
Total & $5.14 \pm 0.56$ & $12.00 \pm 0.31$ & $21.73 \pm 1.02$ & $159.03 \pm 20.77$ & $502.94 \pm 38.31$ \\
GFP $^{+}$ & $13.51 \pm 0.22$ & $17.76 \pm 0.40$ & $25.28 \pm 0.75$ & $164.39 \pm 21.12$ & $514.33 \pm 39.46$ \\
GFP $^{+} \%$ & $9.44 \pm 4.06$ & $49.70 \pm 0.93$ & $81.31 \pm 2.14$ & $96.34 \pm 0.79$ & $97.76 \pm 0.46$ \\
\hline
\end{tabular}

${ }^{a}$ The pelD promoter activities were compared after $0,4,8,12$, and $24 \mathrm{~h}$ of culture in media.

${ }^{\mathrm{b}}$ Green fluorescent protein (GFP) intensity was determined by flow cytometry. The fluorescence intensities were collected, including average GFP fluorescence intensity of total bacterial cells (Total), average GFP fluorescence intensity of GFP-expressing bacterial cells $\left(\mathrm{GFP}^{+}\right)$, and the percentage of GFP-expressing bacterial cells of the total bacterial cells $\left(\mathrm{GFP}^{+} \%\right)$. 
be required for the pathogen to establish its initial interaction within the potato tubers but is not as essential due to the massive nutrition release through pectinase maceration in the later stage of infection (20 to $24 \mathrm{~h}$ after inoculation).

Pectinolytic enzymes of phytopathogenic microorganisms are considered to play two opposing roles during plant infection (Messiaen and van Cutsem 1994). The action of pectic enzymes can breach the structural barrier of the plant cell wall, making the tissue more accessible to other bacterial enzymes. However, the oligogalacturonides released through pectate lyase degradation also can elicit defense responses in hosts. In E. chrysanthemi, PelD is one of the most effective pectinases in causing maceration (Robert-Baudouy et al. 2000; Shevchick et al. 1997). A higher level of pelD expression was observed in Ech131, an hrpL deletion mutant of Ech3937, grown under a pel-inducing condition. The repression of pelD expression through T3SS regulon may help the cells to avoid the host defense response through limiting the release of the oligogalacturonides during the early stage of plant infection. Another recent study also suggested that $k d g T$, an oligogluconate transporter, was upregulated by HrpL (unpublished data). This result suggests that HrpL of Ech3937 also might be able to reduce the host defense response by enhancing the transportation of oligogalacturonides into the bacterial cells from degraded plant tissues. The upregulation of $k d g T$ by $\mathrm{HrpL}$ also might facilitate bacterial growth at the initial infection stage by enhancing the uptake of oligogluconates. In conclusion, our study shows that the Ech3937 regulatory network ties the expression of the pel and $h r p$ regulons together and that only a subpopulation of Ech3937 cells expresses these virulence genes during the multifactorial process of bacterial pathogenesis.

\section{MATERIALS AND METHODS}

\section{Bacterial strains and plasmids.}

The bacterial strains, plasmids, and primers used in this study are listed in Table 1. Ech131, which has a full deletion of the hrpL gene (ASAP ID 15577), was constructed from the parent strain Ech3937 by a crossover PCR method as described (Yang et al. 2002). Wild-type E. chrysanthemi 3937 and its mutant strains were stored at $-80^{\circ} \mathrm{C}$ in $15 \%$ glycerol and grown on Luria-Bertani (LB), King's medium B, or M9 MM supplied with $0.2 \%$ glucose (Gerhardt et al. 1994). Plasmids were isolated from Escherichia coli JM109 using QIAprep spin miniprep kit (Qiagen, Valencia, CA, U.S.A.). Plasmids were introduced into Erwinia chrysanthemi strains by electroporation using a Gene Pulser Electroporation system (BioRad, Hercules, CA, U.S.A.). Antibiotics used were ampicillin, $100 \mu \mathrm{g} / \mathrm{ml}$; chloramphenicol, $50 \mu \mathrm{g} / \mathrm{ml}$; and kanamycin, 50 $\mu \mathrm{g} / \mathrm{ml}$.

\section{Construction \\ of Pmrp, PdspE, and PpelD promoter probe plasmids.}

DNA fragments of mrp promoter regions were PCR amplified from E. chrysanthemi 3937 chromosomal DNA and ligated into the pGEM-T Easy vector system containing 3'T overhangs at the insertion side (Promega Corp., Madison, WI, U.S.A.). The plasmid DNA was sequence confirmed and digested with EcoRI to release the mrp promoter fragment, which was ligated into the promoter-probe vector pPROBE-AT at the EcoRI site. The orientation of the inserted DNA fragments in pPROBE-AT was determined by PCR and the final plasmid construct was designated as Pmrp. The construction of plasmids $\mathrm{P} d s p E$ and $\mathrm{P} p e l D$, which contain the $d s p E$ and pelD promoter regions in vector pPROBE-AT, are described by Yang and associates (2004).
FACS analysis.

The wild-type Ech3937 and hrpL mutant Ech131 carrying pPROBE-AT alone, Pmrp, PdspE, and PpelD, respectively, were grown on LB broth at $28^{\circ} \mathrm{C}$ overnight and transferred to appropriate media. For FACS analysis, samples were collected by centrifuge, washed with $1 \times$ phosphate buffer saline (PBS; 4,000 rpm for $5 \mathrm{~min}$ ), and resuspended in the PBS to an optical density at $600 \mathrm{~nm}$ of 0.1 . As for in planta FACS assays, a volume of $0.5 \mathrm{ml}$ of bacterial suspension from each strain was inoculated into the leaves of the Chinese cabbage and potatoes tubers, respectively, and incubated at $28^{\circ} \mathrm{C}$ for $2,4,8$, and 24 $\mathrm{h}$. The leaves and tubers were sliced into small pieces, placed into $15-\mathrm{ml}$ centrifuge tubes, and centrifuged at 5,000 rpm for $10 \mathrm{~min}$. The intercellular fluids from plant tissues that contained bacterial cells were further separated by centrifuge. The cell pellets then were washed with $1 \times$ PBS and resuspended in $1 \mathrm{ml}$ of $1 \times$ PBS prior to being run on a FACSCalibur flow cytometer (BD Biosiences, San Jose, CA, U.S.A.). Similar procedures were used to investigate the GFP expression of the bacterial constructs in King's medium B and MM. Three replicates were performed for each treatment.

\section{Real time PCR analysis.}

Wild-type Ech3937 or the hrpL mutant Ech131 was grown in MM containing 1\% PGA for $24 \mathrm{~h}$. Total RNA from the bacteria was isolated by using TRI (Sigma-Aldrich, St. Louis, U.S.A.) reagent method and treated with Turbo DNase (Ambion, Austin, TX, U.S.A.) followed by phenol/chloroform extraction and isopropenol precipitation. An iScript cDNA synthesis kit (Bio-Rad, Hercules, CA, U.S.A.) was used to synthesize cDNA from $0.5 \mu \mathrm{g}$ of treated total RNA. The iQ SYBR Green Supermix (Bio-Rad) was used for real-time PCR reaction to quantify the cDNA level of pelD and $r p l U$ in different samples (Mah et al. 2003). Standard curves used to quantify relative cDNA level were made from 10 -fold serial dilution of genes of interest (Winer et al. 1999). The $r p l U$ was used as the internal control to normalize the cDNA input of each sample. Reactions were run and data were collected by the Opticon 2 system (Bio-Rad).

\section{ACKNOWLEDGMENTS}

This project is supported by grants from a Graduate Research Award from the University of Wisconsin-Milwaukee, the National Science Foundation (award no. MCB-0211750), UW-Madison graduate school, and by a Hatch Project 4605. We would like to thank D. I. Keen and M. L. P. Collins for review of this manuscript, X.-Y. Shi and Q. Zhang for technical support, and the undergraduate and graduate students of the University of Wisconsin-Milwaukee who contributed to this research work in their Bio Sci 580 course in spring 2005.

\section{LITERATURE CITED}

Alfano, J. R., and Collmer, A. 1997. The type III (Hrp) secretion pathway of plant pathogenic bacteria: trafficking harpins, Avr proteins, and death. J. Bacteriol. 179:5655-5662.

Alfano, J. R., and Collmer, A. 2004. Type III secretion system effector proteins: double agents in bacterial disease and plant defense. Annu. Rev. Phytopathol. 42:385-414.

Bauer, D. W., Bogdanove, A. J., Beer, S. V., and Collmer, A. 1994. Erwinia chrysanthemi hrp genes and their involvement in soft rot pathogenesis and elicitation of the hypersensitive response. Mol. Plant-Microbe Interact. 7:573-581.

Bauer, D. W., Wei, Z. M., Beer, S. V., and Collmer, A. 1995. Erwinia chrysanthemi harpinEch: an elicitor of the hypersensitive response that contributes to soft-rot pathogenesis. Mol. Plant-Microbe Interact. 8:484-491.

Boccara, M., and Chatain, V. 1989. Regulation and role in pathogenicity of Erwinia chrysanthemi 3937 pectin methylesterase. J. Bacteriol. 171:4085-4087.

Castillo, A., and Reverchon, S. 1997. Characterization of the pecT control region from Erwinia chrysanthemi 3937. J. Bacteriol. 179:4909-4918. 
Dye, B. T., Schell, K., Miller, D. J., and Ahlquist, P. 2005. Detecting protein-protein interaction in live yeast by flow cytometry. Cytometry 63A:77-86.

Gerhardt, P., Murray, R. G. E., Wood, W. A., and Krieg, N. R. 1994. Methods for General and Molecular Bacteriology. American Society for Microbiology Press, Washington, DC, U.S.A.

Ham, J. H., Cui, Y., Alfano, J. R., Rodriguez-Palenzuela, P., Rojas, C. M., Chatterjee, A. K., and Collmer, A. 2004. Analysis of Erwinia chrysanthemi EC16 pelE::uidA, pelL::uidA, and hrpN::uidA mutants reveals strain-specific atypical regulation of the Hrp type III secretion system. Mol. Plant-Microbe Interact. 17:184-194.

Hugouvieux-Cotte-Pattat, N., and Robert-Baudouy, J. 1992. Analysis of the regulation of the pelBC genes in Erwinia chrysanthemi 3937. Mol. Microbiol. 6:2363-2376.

Hugouvieux-Cotte-Pattat, N., Condemine, G., Nasser, W., and Reverchon, S. 1996. Regulation of pectinolysis in Erwinia chrysanthemi. Annu. Rev. Microbiol. 50:213-257.

Jafra, S., Figura, I., Hugouvieux-Cotte-Pattat, N., and Lojkowska, E. 1999. Expression of Erwinia chrysanthemi pectinase genes pelI, pelL, and pelZ during infection of potato tubers. Mol. Plant-Microbe Interact. 12:845-851.

Jin, Q., Thilmony, R., Zwiesler-Vollick, J., and He, S. Y. 2003. Type III protein secretion in Pseudomonas syringae. Microbes Infect. 5:301310

Kazemi-Pour, N., Condemine, G., and Hugouvieux-Cotte-Pattat, N. 2004 The secretome of the plant pathogenic bacterium Erwinia chrysanthemi. Proteomics 4:3177-3186.

Laing, E., and Pretorius, I. S. 1993. Co-expression of an Erwinia chrysanthemi pectate lyase-encoding gene (pelE) and an E. carotovora polygalacturonase-encoding gene (peh1) in Saccharomyces cerevisiae. Appl. Microbiol. Biotechnol. 39:181-188.

Lopez-Solanilla, E., Llama-Palacios, A., Collmer, A., Garcia-Olmedo, F. and Rodriguez-Palenzuela, P. 2001. Relative effects on virulence of mutations in the sap, pel, and hrp loci of Erwinia chrysanthemi. Mol. Plant-Microbe Interact. 14:386-393.

Mah, T. F., Pitts, B., Walker, G. C., Stewart, P. S., and O'Toole, G. A. 2003. A genetic basis for Pseudomonas aeruginosa biofilm antibiotic resistance. Nature 426:306-310.

Marits, R., Tshuikina, M., Pirhonen, M., Laasik, E., and Mae, A. 2002. Regulation of the expression of prtW::gusA fusions in Erwinia carotovora subsp. carotovora. Microbiology 148:835-842.

Messiaen, J., and van Cutsem, P. 1994. Pectic signal transduction in carrot cells: membrane, cytosolic and nuclear responses induced by oligogalacturonides. Plant Cell Physiol. 35:677-689.

Miller, W. G., Leveau, J. H., and Lindow, S. E. 2000. Improved $g f p$ and inaZ broad-host-range promoter-probe vectors. Mol. Plant-Microbe Interact. 13:1243-1250.

Nasser, W., Robert-Baudouy, J., and Reverchon, S. 1997. Antagonistic effect of CRP and KdgR in the transcription control of the Erwinia chrysanthemi pectinolysis genes. Mol. Microbiol. 26:1071-1082.

Nasser, W., Shevchik, V. E., and Hugouvieux-Cotte-Pattat, N. 1999. Analysis of three clustered polygalacturonase genes in Erwinia chrysanthemi 3937 revealed an anti-repressor function for the PecS regulator. Mol. Microbiol. 34:641-650.

Nomura, K., Nasser, W., Kawagishi, H., and Tsuyumu, S. 1998. The pir gene of Erwinia chrysanthemi EC16 regulates hyperinduction of pectate lyase virulence genes in response to plant signals. Proc. Natl. Acad. Sci. U.S.A. 95:14034-14039.

Okinaka, Y., Yang, C. H., Perna, N. T., and Keen, N. T. 2002. Microarray profiling of Erwinia chrysanthemi 3937 genes that are regulated during plant infection. Mol. Plant-Microbe Interact. 15:619-629.

Park, H. S., Schumacher, R., and Kilbane, J. J., 2nd. 2005. New method to characterize microbial diversity using flow cytometry. J. Ind. Microbiol. Biotechnol. 32:94-102.

Py, B., Loiseau, L., and Barras, F. 1999. Assembly of the type II secretion machinery of Erwinia chrysanthemi: direct interaction and associated conformational change between OutE, the putative ATP-binding component and the membrane protein OutL. J. Mol. Biol. 289:659-670.

Ramprasad, M. P., Terpstra, V., Kondratenko, N., Quehenberger, O., and Steinberg, D. 1996. Cell surface expression of mouse macrosialin and human $\mathrm{CD}_{68}$ and their role as macrophage receptors for oxidized low density lipoprotein. Proc. Natl. Acad. Sci. U.S.A. 93:14833-14838.

Reverchon, S., Nasser, W., and Robert-Baudouy, J. 1991. Characterization of $k d g R$, a gene of Erwinia chrysanthemi that regulates pectin degradation. Mol. Microbiol. 5:2203-2216.

Robert-Baudouy, J., Nasser, W., Condemine, G., Reverchon, S., Schevchik, S., and Hugouvieux-Cotte-Pattat, N. 2000. Pectic enzymes of Erwinia chrysanthemi, regulation and role in pathogenesis. Pages 221-268 in: Plant-Microbe Interactions, Vol. 5. G. Stacey and N. T Keen, eds. American Phytopathological Society Press, St. Paul, MN, U.S.A.

Rojas, C. M., Ham, J. H., Schechter, L. M., Kim, J. F., Beer, S. V., and Collmer, A. 2004. The Erwinia chrysanthemi EC16 hrp/hrc gene cluster encodes an active Hrp type III secretion system that is flanked by virulence genes functionally unrelated to the Hrp system. Mol. PlantMicrobe Interact. 17:644-653.

Roy, C., Kester, H., Visser, J., Shevchik, V., Hugouvieux-Cotte-Pattat, N. Robert-Baudouy, J., and Benen, J. 1999. Modes of action of five different endopectate lyases from Erwinia chrysanthemi 3937. J. Bacteriol. 181:3705-3709.

Sergent-Tanguy S., Chagneau C., Neveu I., and Naveilhan P. 2003. Fluorescent activated cell sorting (FACS): a rapid and reliable method to estimate the number of neurons in a mixed population. J. Neurosci. Methods 129:73-79.

Shevchik, V. E., and Hugouvieux-Cotte-Pattat, N. 1997. Identification of a bacterial pectin acetyl esterase in Erwinia chrysanthemi 3937. Mol. Microbiol. 24:1285-1301.

Shevchik, V. E., and Hugouvieux-Cotte-Pattat, N. 2003. PaeX, a second pectin acetylesterase of Erwinia chrysanthemi 3937. J. Bacteriol. 185:3091-3100

Shevchik, V. E., Robert-Baudouy, J., and Hugouvieux-Cotte-Pattat, N. 1997. Pectate lyase PelI of Erwinia chrysanthemi 3937 belongs to a new family. J. Bacteriol. 179:7321-7330.

Shevchik, V. E., Condemine, G., Robert-Baudouy, J., and HugouvieuxCotte-Pattat, N. 1999. The exopolygalacturonate lyase PelW and the oligogalacturonate lyase Ogl, two cytoplasmic enzymes of pectin catabolism in Erwinia chrysanthemi 3937. J. Bacteriol. 181:3912-3919.

Wan, Y. Y., and Flavell, R. A. 2005. Identifying Foxp3-expressing suppressor $\mathrm{T}$ cells with a bicistronic reporter. Proc. Natl. Acad. Sci. U.S.A. 102:5126-5131.

Winer, J., Jung, C. K., Shackel I., and Williams P. M. 1999. Development and validation of real-time quantitative reverse transcriptase-polymerase chain reaction for monitoring gene expression in cardiac myocytes in vitro. Anal. Biochem. 270:41-49.

Yang, C. H., Gavilanes-Ruiz, M., Okinaka, Y., Vedel, R., Berthuy, I., Boccara, M., Chen, J. W., Perna, N. T., and Keen, N. T. 2002. hrp genes of Erwinia chrysanthemi 3937 are important virulence factors. Mol. Plant-Microbe Interact. 15:472-480.

Yang, S., Perna, N. T., Cooksey, D. A., Okinaka, Y., Lindow, S. E., Ibekwe, A. M., Keen, N. T., and Yang, C. H. 2004. Genome-wide identification of plant-upregulated genes of Erwinia chrysanthemi 3937 using a GFPbased IVET leaf array. Mol. Plant-Microbe Interact. 17:999-1008.

Yap, M. N., Yang, C. H., Barak, J. D., Jahn, C. E., and Charkowski, A. O. 2005. The Erwinia chrysanthemi Type III secretion system is required for multicellular behavior. J. Bacteriol. 187:639-648

\section{AUTHOR-RECOMMENDED INTERNET RESOURCE}

University of Wisconsin ASAP (a systematic annotation package for community analysis of genomes) website; asap.ahabs.wisc.edu/asap/ASAP1.htm 